\title{
Migrações de regresso a Portugal: uma história sem fim*
}

\author{
Filipa Pinho (https://orcid.org/0000-0002-8258-1157), \\ Universidade de Coimbra, Coimbra, Portugal'.
}

José Carlos Marques (https://orcid.org/0000-0002-4690-5943), Instituto Politécnico de Leiria, Leiria, Portugal".

Pedro Góis (https://orcid.org/0000-0002-5217-0285), Universidade de Coimbra, Coimbra, Portugal"'.

Resumo: Neste artigo analisamos os regressos da emigração portuguesa a Portugal numa perspetiva histórica, com base na literatura científica de maioria portuguesa produzida desde os anos 1980 sobre o tema. Com este conjunto dos trabalhos disponíveis é possível reconstituir o padrão dos regressos através do volume contabilizado nos censos (ou de outras formas), conhecer perfis de regressados e avaliar algum do impacto dos regressos no desenvolvimento das regiões de origem, atendendo a que a quase totalidade dos regressados se dirige para a mesma região de onde havia saído. Reconstruímos o padrão dos regressos e analisamos o perfil dos regressados com informação dos fluxos entre os anos 1980 e 2011 a partir de revisão da literatura existente; os indicadores do Eurostat permitem análise do volume mais recente das migrações de regresso. Constatamos uma relativa homogeneidade no perfil e dos regressos do passado, ao contrário da diferenciação dos regressos posteriores, resultantes de uma emigração que também se diversificou.

Palavras-chave: Migração de regresso. Portugal. Emigração portuguesa. História. Indicadores.

\section{Return migration to Portugal: a never ending history}

Abstract: In this paper we analyse return migration to Portugal in a historical perspective, most based on the Portuguese scientific literature produced on the subject, particularly since the 1980s. With this works available, it is possible to reconstruct the pattern of returns through its volume recorded in the censuses (or in other ways), to know returnees' profiles and to evaluate some of the return impact on the development of the regions of origin, given that almost all returnees go to the same region from which they left. We reconstructed the pattern of returns and the profile of returnees according to the information of flows between the 1980s and 2011 from the existing literature review; Eurostat indicators allow the analysis of more recent return migration volume. We verify a relative homogeneity in the profile of the returns from the past, in contrast to the differentiation of the subsequent returns, which result from an out-migration that has also diversified.

Keywords: Return migration. Portugal. Portuguese out-migration. History. Indicators.

\author{
* Este artigo foi \\ elaborado no \\ âmbito do projeto \\ "Experiências \\ e expectativas \\ de regresso dos \\ novos emigrantes \\ portugueses: \\ reintegração e \\ mobilidades" \\ (Eernep), financiado \\ pela Fundação \\ para a Ciência e a \\ Tecnologia (Portugal) \\ com a referência \\ PTDC/SOC- \\ SOC/28730/2017, \\ em curso desde \\ outubro de 2018 e \\ com duração de 36 \\ meses. \\ I. Filipa Pinho é \\ investigadora de \\ pós-doutoramento \\ no Centro de \\ Estudos Sociais da \\ Universidade de \\ Coimbra, no núcleo \\ Humanidades, \\ Migrações e \\ Estudos para a Paz \\ (Nhumep), Centro \\ de Estudos Sociais \\ da Universidade de \\ Coimbra, Portugal. \\ <pinho.filipa@gmail. \\ com>.
}

II. José Carlos Marques é doutor em sociologia e professorcoordenador principal do Instituto Politécnico de Leiria e Investigador do CICS.NOVA.IPLeiria, Leira, Portugal. <jclaranjo@gmail. com>.

III. Pedro Góis é doutor em sociologia 
e professor na Faculdade de Economia, Investigador do Centro de Estudos Sociais da Universidade de Coimbra. <pmgois@gmail. com>.

\section{Introdução}

$\Lambda$

s migrações de regresso a Portugal constituem, em rigor, o reverso da emigração portuguesa; por outras palavras, são contracorrentes migratórias de uma emigração anterior que frequentemente traz associada a ideia de retorno (Sayad, 2000) e integram o padrão migratório português, a história da emigração portuguesa. À semelhança dos movimentos emigratórios, os regressos são influenciados simultaneamente pelos contextos estruturais e conjunturais de Portugal e dos países de acolhimento, o que significa que qualquer dos movimentos pode intensificar-se quando ocorrem mudanças sociais num, ou em ambos os polos, isto tendo por referência apenas as condições estruturais macro. Noutros níveis de análise, também devem ser considerados os contextos individuais ou familiares dos emigrantes.

Na história contemporânea são claramente identificáveis três grandes períodos na emigração portuguesa conforme os destinos para onde se dirige, ainda que no terceiro haja uma maior heterogeneidade e ainda esteja a decorrer. Num primeiro, entre o final do século XIX e o final da Segunda Guerra Mundial, os fluxos dirigiam-se maioritariamente para destinos transatlânticos, como o Brasil e os Estados Unidos; no segundo momento, entre o final dos anos de 1950 e 1974, os destinos são, sobretudo, os dos países do centro e norte da Europa, como a França e a Alemanha. A partir de meados dos anos 1980 do século XX, com a orientação da emigração para a Suíça e o Luxemburgo, continua a diversificação dos destinos, mas numa lógica predominantemente europeia que se mantém até hoje a que corresponde o terceiro período identificado. Na viragem para o século XXI adquire importância - Reino Unido, a Espanha e, com a intensificação da emigração na última década, retoma-se o destino francês e alemão (Pires et al., 2010; Peixoto et al., 2016; Góis \& Marques 2020).

A cada um desses três períodos sucederam regressos de intensidade variável, documentados na literatura das migrações nacionais. Não se previam regressos expressivos das migrações transoceânicas, sempre vistas como uma emigração mais permanente (Silva, 1984), mas estes foram sempre existindo (Cónim, 1984b), merecendo análise, por exemplo, os "brasileiros de torna viagem" (Alves, 1994), isto é, portugueses que regressavam às suas regiões de origem, após um período mais ou menos longo de residência no Brasil (Monteiro, 2000; Maia, 2009; Rowland, 1999a; 1999b). Vários estudos de caso realizados, sobretudo na região norte de Portugal, mostraram uma realidade de regresso de difícil quantificação mas passível de uma caracterização que aponta para a enorme influência social e sociológica destes regressos na esfera local (Piloto, 2010). Isabel Tiago Oliveira comparou os valores da 
emigração legal e do saldo migratório em Portugal entre 1890 e 1970, verificando um significativo movimento de regresso entre 1890 e 1940, bem como um predomínio de um movimento de re-emigração entre 1940 e 1970 (Oliveira, 2007). Emigração e regresso, e regresso e re-emigração surgem, assim, como fenómenos interligados numa sequência de migrações que compõem o padrão migratório português.

O regresso dos que emigraram durante o segundo período (1950-1974) mereceu uma maior atenção (sobretudo em textos dos anos 1980 e 1990), porque entre finais de 1973 e início de 1974, os países europeus de acolhimento suspenderam a entrada de novos trabalhadores estrangeiros e, portanto, os trabalhadores têm de se confrontar com a ideia de ficar ou de regressar à origem. Dois artigos de Michel Poinard, de 1983, terão sido os primeiros trabalhos publicados sobre o regresso de portugueses de países europeus (Poinard 1983a; 1983b). No primeiro artigo, são analisados 3.792 processos de portugueses que residiam em França e que, sendo elegíveis por residirem ininterruptamente em França durante cinco anos, aproveitaram as ajudas ao regresso criadas pelo governo francês. No segundo, apresenta-se um inquérito a regressados de França, administrado a residentes em cinco concelhos (Sabugal, Bragança, Guimarães, Serpa e Lisboa). Em conjunto, estes dois estudos mostram a relevância dos apoios ao regresso por parte dos países de emigração e que ter condições económicas desfavoráveis não é suficiente para a explicação de como o regresso se insere no projeto migratório do emigrante. Evidenciam, também, que o regresso coloca constrangimentos e desafios particulares aos contextos regionais de origem dos emigrantes, que tinham encontrado nestes um amortecedor para o seu progressivo declínio. Regressar à origem significa, em muitos casos, uma necessidade de reencontrar um equilíbrio entre formas de viver num passado que pouco mudou, e, por outro lado, toda uma mudança, entretanto tornada um novo habitus, de que se não quer abdicar. Por outras palavras, os emigrantes regressados durante os anos 1980 vinham de países mais desenvolvidos do que Portugal à época, pois apenas em 1986 o país adere à então Comunidade Económica Europeia (CEE), e ainda demoram a ser visíveis os efeitos da entrada dos fundos comunitários na formação e nos investimentos em infraestruturas. Regressar é viver entre o mundo dos pais e o mundo dos filhos, entre a casa entretanto construída e a lavoura herdada, entre uma libertação da mulher do monopólio do trabalho doméstico e a desconfiança de uma sociedade tradicional (Rodrigues, 2011). A incorporação das mulheres portuguesas na análise da emigração e do regresso, realizada de forma pioneira por Caroline Brettell, traz para os estudos sobre o regresso novas dimensões de análise que mostram não apenas a importância da emigração no ciclo de vida individual, mas simultaneamente na sociedade portuguesa, demonstrando também o papel desempenhado por quem fica (Santos \& Brettell, 1978; Brettell, 1983). 
1. O Instituto que organizou este repatriamento designava-se "Instituto de Apoio ao Regresso de Nacionais" e foi criado para apoiar regressos dos países europeus. Devido à descolonização, ficou associado ao repatriamento de África e a sua designação acabou por se refletir no epíteto atribuído aos repatriados.

2. Paralelamente, foram sendo publicadas reflexões exclusivamente teóricas sobre o conceito de regresso (Rocha-Trindade, 1984), ou de como este depende de circunstâncias histórico-sociais que configuram as opções migratórias disponíveis (Costa, 2001).
Uma referência incontornável nos estudos sobre o regresso de emigrantes portugueses neste segundo período é o projeto financiado pela Fundação Volkswagenwerk e publicado pelo Instituto de Estudos para o Desenvolvimento (Silva et al., 1984). Através de inquérito a uma amostra representativa de emigrantes regressados ao continente após 1970, a qual foi definida com base nos dados oficiais sobre o volume da emigração, é possível inteirar-se, de forma aprofundada, acerca dos perfis dos emigrantes regressados dos países europeus e a análise da sua reinserção no país, para também aferir o impacto destes movimentos no desenvolvimento regional. Este estudo de âmbito nacional foi retomado por Rogério Roque Amaro em publicações posteriores que incluíram dados dos censos de 1981 (Amaro, 1985a; 1985b). A coordenadora Manuela Silva também publicou um artigo posterior com base numa comunicação sobre este projeto (Silva, 1984).

Os trabalhos referidos permitiram que fossem sendo conhecidos notadamente os quantitativos do regresso da vaga de emigração dos anos 1960, o perfil dos regressados e a influência que exerceram na sociedade portuguesa (Rocha-Trindade \& Arroteia, 1984; Candeias, Marques \& Peixoto, 2014). Ao longo dos anos também se multiplicaram os estudos de âmbito mais regional e localizado sobre estas populações, como: a emigração e os regressos na Beira Interior (Martins, 1986); o regresso e o desenvolvimento no Nordeste interior português (Cepeda, 1991); a influência das populações regressadas e retornadas na alteração de comportamentos, consumo e modo de vida em três concelhos do distrito de Viseu (Sátão, Tondela e Viseu) (Santos, 1991); as estratégias de subsistência das famílias de regressados, as suas características socioeconómicas e as transformações da estrutura socioeconómica e demográfica no concelho de Ponte de Lima (Roca, 2000); os movimentos de emigração e de regresso ocorridos entre uma freguesia de Bragança (Pinela) e Paris (Portela \& Nobre, 2001); o regresso de emigrantes à NUT III Pinhal Interior Sul, com a realização de 656 inquéritos sobre características, motivações e processos de reintegração dos regressados (Martins, 2003).

Aos repatriados na sequência da descolonização de África também se dedicou atenção, em modalidade de comparação de perfis com outros regressados (Santos, 1991),ou de forma aprofundada e exclusiva (Pires \& Silva 1987; Pires, 2003). Os protagonistas destes repatriamentos ficaram conhecidos como "retornados" ${ }^{1}$, embora neste grupo estivessem incluídos descendentes que, em rigor, não estariam a retornar. A investigação que incide simultaneamente sobre os emigrantes regressados da Europa ou de África, habitualmente distingue-os como "regressados" e "retornados", respetivamente; já nos estudos dedicados apenas aos regressados da Europa, é mais comum utilizar a designação de regresso². 
Para a análise do volume e perfis sociodemográficos dos regressos ocorridos já nos anos 2000, cuja origem já engloba a "nova" emigração (além da tradicional), o património encontrado é mais reduzido. Este terceiro período da emigração portuguesa, por ser ainda muito recente, ter destinos diversificados, e estar ainda a decorrer, necessita ainda de uma maior atenção por parte dos investigadores. Devem ser citadas as publicações de Isabel Oliveira e colegas (Oliveira et al., 2016; Oliveira et al., 2017), resultantes de um projeto sobre a emigração portuguesa do século $X X I$, cujos contributos começaram a contrariar a tendência de desconhecimento generalizado sobre regressos mais recentes.

Também já no século XXI, aprofundou-se o conhecimento de categorias específicas de emigrantes e/ou regressados, como os cientistas e a sua reintegração em Portugal (Delicado, 2010), ou descendentes de emigrantes e os seus "regressos" (Sardinha, 2008; 2011; Neto, 2010, 2016; Neto \& Neto, 2011) que, em muitos casos, correspondem à primeira emigração para o país de origem dos antecessores e são designados pelo conceito de "contra-diáspora" (King \& Christou 2010; 2011). O estudo do regresso a uma freguesia rural e as dinâmicas de reinserção familiar associadas é um outro exemplo de análise onde a família assume um papel relevante (Leandro, 2002).

A investigação centrada no potencial do regresso, portanto a jusante do processo e não depois da sua concretização, também tem alguma representação no conjunto da produção referida. Subjacente a estes questionamentos, estará a ideia de aferir se de facto "o retorno é naturalmente o desejo e o sonho de todos os imigrantes" (Sayad, 2000: 11). Além de um estudo recente sobre este tema, conjugado com o potencial de empreendedorismo (Góis, Marques \& Pinho, 2017), diversas referências sobre a emigração portuguesa contemplam o tema das motivações, desejos ou intenções de regresso quando inquirem os emigrantes sobre as suas trajetórias migratórias e de inserção social (Fontes, 2007; Sardinha, 2008; Correia, 2015; Pereira, Pinto \& Pires, 2015; Peixoto et al., 2016).

Antes de passarmos a uma análise mais detalhada, sublinhe-se que, tal como a emigração portuguesa nunca foi interrompida (Pires et al., 2010), os regressos também nunca cessaram (Oliveira et al., 2016; Oliveira et al., 2017), ainda que estes não tenham nunca merecido análises tão extensas como a emigração. De facto, apenas 8\% de referências na bibliografia sobre emigração portuguesa, entre 1980 e 2013, foram dedicadas ao regresso dos emigrantes portugueses (Candeias et al., 2014).

Em segundo lugar, e tal como acontece na bibliografia internacional, os trabalhos salientam frequentemente as dificuldades inerentes à recolha de dados sobre o 


\section{Alguma}

informação anual é possível obter a partir das estatísticas mais recentes publicadas no Eurostat.

\section{Existe produção} científica portuguesa, ou em colaboração com colegas brasileiros, sobre retorno de emigrantes brasileiros ao Brasil, com origem nos Estados Unidos da América e na Europa (por exemplo, Pereira \& Siqueira, 2013). Este texto centra-se no regresso a Portugal, de modo que estes trabalhos poderão ser referenciados em eventuais futuros textos comparativos. volume e a dinâmica dos regressos, assim como sobre o perfil dos regressados. É assumido que as estatísticas dos censos são as mais apropriadas para identificar o volume aproximado e o padrão de regressos num determinado período, através de perguntas relativas à residência dos indivíduos em data(s) anterior(es) à censitária, mas ressalvam-se algumas limitações:

i. nas estatísticas dos censos não são contabilizados os filhos de emigrantes que também tenham regressado, mas que tenham nascido fora das datas retrospetivas;

ii. nem todos os residentes no estrangeiro em datas anteriores preenchem a condição de emigrante;

iii. não entram nas estatísticas os regressados que tenham morrido antes da data censitária e não se tem acesso a variações anuais do número de regressados (Amaro, 1985b; Cepeda, 1991; Martins, 2004) . $^{3}$

Para colmatar limitações nos objetivos de caracterização mais detalhada sobre o regresso, nomeadamente as motivações para o regresso, o destino das poupanças e as modalidades de investimentos, entre outras, foram feitos em inquéritos de âmbito nacional (Silva, 1984; Silva et al., 1984) ou local (Poinard, 1983b; Cepeda, 1991; Santos, 1991; Martins, 2003), e analisados dados administrativos ou processuais (Poinard, 1983a).

Nas secções seguintes analisamos os regressos da emigração portuguesa numa perspetiva histórica, maioritariamente com base na literatura científica portuguesa, mas que inclui também autores estrangeiros que se dedicaram ao tema ${ }^{4}$ produzida desde os anos 1980. Com o conjunto dos trabalhos disponíveis, é possível reconstituir o seu padrão através do volume contabilizado nos censos (ou de outras formas), conhecer perfis de regressados e avaliar algum do seu impacto no desenvolvimento das regiões de origem, atendendo a que a quase totalidade dos regressados se dirige para a mesma freguesia de onde havia saído (Poinard 1983a; Silva 1984; Amaro 1985b; Cepeda, 1991; Roca, 2000). Reconstruímos o padrão dos regressos e o perfil dos regressados de acordo com o volume dos fluxos entre os anos 1980 e 2011, a partir da literatura e, posteriormente, com base nos indicadores do Eurostat. 


\section{O conceito de regresso subjacente nos estudos}

A maioria dos trabalhos sobre o regresso de emigrantes a Portugal concentra-se nos movimentos que, em grande parte, resultaram de políticas dos países de acoIhimento, nos anos 1980, destinadas a incentivar financeiramente o regresso dos imigrantes que se encontravam em seus territórios. Assumia-se que as dificuldades inerentes à reintegração nos regressos poderia conduzir a uma re-emigração, mas também se admitia que voltar a sair não estava, em princípio, previsto quando se construiu a decisão de regressar (Amaro 1985a: 356), isto é, estes movimentos não se realizavam numa perspetiva de migração circular ou repetida. Os regressos pareciam significar um "fecho do ciclo da emigração", a que não será alheio o facto de uma parte destes movimentos ter a referida vertente de decisão política - "não é a vivência do migrante que o leva a colocar o problema do regresso em termos irremediáveis, mas sim uma decisão política sobre a qual não tem voz" (Poinard 1983a: 31). A propósito do regresso de homens portugueses à origem, Francisco Cepeda (1991: 28) afirma que "com o fechar do ciclo natural de emigração o Nordeste (transmontano) assiste ao refazer das relações de masculinidade, já que o regresso Ihe traz de volta os homens que outrora partiram" (grifos nossos).

Maria Beatriz Rocha-Trindade definiu o conceito de regresso - ou regresso e repatriação - como "a mesma situação dinâmica de movimento de quem está fora de um âmbito ou de um contexto e nele volta a inserir-se" e salienta que os conceitos podem variar consoante o tempo, o espaço geográfico, o âmbito legal, ou o serem auto ou hétero definidos (Rocha-Trindade, 1984: 87) . Michel Poinard encontrou regressos anteriores com durações relativamente longas devido a "razões familiares, de saúde, pessoais ou acidentes" e detetou, em entrevistas a emigrantes regressados que, para estes, "a noção de regresso não implica que ele seja definitivo", pois "a maioria deles conserva os seus cartões de permanência até ao limite da validade, persuadidos ou (fingindo) de que poderão ainda voltar a partir, se for necessário" (Poinard, 1983b: 272). A estes regressos anteriores, o autor chama "práticas de vai e torna" (Poinard, 1983b: 272). Por seu turno, Rocha-Trindade assinala que as férias quase assumem aspetos de regressos cíclicos (1984), pois os emigrantes retomam suas atividades familiares e domésticas como se nunca tivessem partido.

A polissemia do conceito de regresso pode ser ainda hoje verificada, como demonstraremos, nos novos perfis da emigração portuguesa e nas novas dinâmicas inerentes ao regresso que desafiam o conceito de regresso como fim do ciclo migratório (Oliveira et al., 2016).
5. A autora detalha, no seu texto, algumas diferenças políticas e de conotação entre regresso/retorno e repatriação, nomeadamente que este último ficou associado ao regresso a expensas do estado. Ainda informa que o primeiro Conselho das Comunidades Portuguesas, em 1981, recomendou o uso do termo regresso "sempre que a deslocação para o país seja voluntária" e o uso do termo retorno sempre que a saída do país de acolhimento seja compulsiva (RochaTrindade, 1984: 91). 


\section{Os regressos nunca terminaram}

6. Fontes: Secretaria de Estado da Emigração (portuguesa) e registos anuais da imigração portuguesa pelo Office National d'Immigration de França (Amaro, 1985b).

7. Jean Rallu, Francisco MunozPerez e Maria José Carrilho (2000), referemse explicitamente à naturalidade. Mas no estudo de Manuela Silva e colegas (1984), por exemplo, são referidos emigrantes portugueses ou regressados portugueses e não é claro se foram apurados os quantitativos referentes a pessoas com naturalidade portuguesa (que, tendo residido fora, efetivamente regressaram), a pessoas com nacionalidade portuguesa (inclui quem possa ter nascido fora e nunca ter residido em Portugal), ou a pessoas que acumulam as duas condições (nascidas em Portugal e detentoras de nacionalidade portuguesa).
Os regressos de emigrantes portugueses avolumaram-se após 1973-1974 - principalmente se considerarmos a repatriação após a descolonização - e tiveram um pico em 1980, após processos estatais de apoio ao regresso por parte dos governos europeus, em resultado das crises ocorridas com os choques petrolíferos. Os contingentes envolvidos na repatriação ter-se-ão situado entre 500 e 700 mil indivíduos "retornados", segundo o Instituto de Apoio ao Regresso de Nacionais (Iarn), entre 1974 e 1976 (Amaro 1985b: 607). Dados publicados (e os microdados não publicados) do XII Recenseamento Geral da População, de 1981, apontam para um o número de repatriados um pouco abaixo, com 471 mil (Pires, 2003: 192).

Para conhecermos os números dos regressos da emigração intraeuropeia temos de conhecer os números associados à emigração. Entre 1960 e 1974, terá havido um milhão e 500 mil saídas de Portugal, 180 mil só no ano de 1970, e, em 1973, este número era, ainda, de 123 mil (ano em que começa a inflexão no movimento emigratório nacional) ${ }^{6}$. No apuramento dos regressos, o indicador mais utilizado parte dos censos e de dados combinados entre a residência no momento censitário e as perguntas retrospetivas sobre o local de residência. Como já foi referido, apesar de haver um consenso generalizado em torno do procedimento para quantificar os movimentos de regresso, esta metodologia não é isenta de limitações. Podem ser assinalados dois exemplos:

i. ao censo de 1970 seguiu-se o de 1981 (11 anos depois), tendo sido depois disso sempre de 10 em 10 anos;

ii. em geral, as perguntas retrospetivas são sobre o local/país de residência um ano e cinco anos antes, mas, nos censos de 1981, e para contabilizar o regresso das ex-colónias, perguntou-se a data de residência dos respondentes em 31 de dezembro de 1973. Estas diferenças, e a pergunta retrospetiva em relação à residência só consta dos censos a partir de 1960, tornam difícil a análise de séries longas (Martins, 2004).

O volume dos fluxos de regresso ao longo dos anos consta do Quadro 1. Em rigor, os valores apresentados não seriam comparáveis. Se, por um lado, têm origem em fontes diferentes, por outro, nem sempre temos a certeza de estar a comparar a mesma variável (nacionalidade ou naturalidade) ${ }^{7}$. Abstraindo-nos dessas limitações, observando os valores é possível identificar um volume de regressos residual em 1960, um aumento muito significativo a partir de 1974, com um pico em 1980, e, depois, 
uma descida para valores médios anuais na ordem de duas dezenas de milhares de regressos, na primeira metade do século XXI. Ao analisar os dados detalhadamente, nota-se, entre 1986 e 1991, uma diminuição generalizada do número de regressados, comparando com o quinquénio anterior ao censo de 1981. No quinquénio anterior ao censo seguinte (entre 1996 e 2001), houve um acréscimo de quase 20,5 mil ex-emigrantes portugueses, em relação ao período de 1986-1991 (Martins, 2004).

No plano distrital, nos censos de 1960, apenas Lisboa apresentou um nível de regressos superior a mil indivíduos (Martins, 2004). Em 1970, esse número foi ultrapassado em Lisboa, Aveiro, Porto e Braga e, em 1980, todos os distritos do continente, com exceção de Portalegre, Évora e Beja, tiveram mais de mil regressos (Martins, 2004). Aveiro, Braga, Lisboa e Porto ultrapassaram, mesmo, os 5.000 regressos.

Em estudo com análise de nível regional de estatísticas administrativas de regressos, entre 1955 e 1973, Norberto Santos (1991) nota que, entre 1955 e 1959, o número de regressados definitivos, por via marítima, não ultrapassou os mil indivíduos em nenhum distrito e só no

\section{REGRESSOS DE EMIGRANTES}

PORTUGUESES ENTRE 1960 E 2018

\begin{tabular}{|c|c|}
\hline Fontes & \\
\hline Censos & $\mathrm{N} /$ média anual \\
\hline Entre 31 Dez. 1959 e 31 Dez. 1960 (1960) & 6.800 \\
\hline Entre 31 Dez. 1965 e 31 Dez. 1970 (1966-70) & $22.000 / 4.400$ (ano) \\
\hline Entre 31 Dez. e 31 Dez. 1970 (1970) & 13.000 \\
\hline Entre 31 Dez. 1973 e 16 Mar. 1981 (1974-80) & 182.190/26.027 (ano) \\
\hline Entre 31 Dez. 1979 e 16 Mar. 1981 (1980) & 60.699 \\
\hline 1986-1991 & $121.398 / 24.280$ (ano) \\
\hline 1996-2001 & 141.857/28.371 (ano) \\
\hline 2001-2011 & $233.000 / 23.300$ (ano) \\
\hline Estimativas & $\mathrm{N} / \mathrm{média} \mathrm{anual}$ \\
\hline 1961-65 & $12.400 / 2.480$ (ano) \\
\hline 1966-70 & $71.000 / 14.200$ (ano) \\
\hline 1971-75 & $183.900 / 36.780$ (ano) \\
\hline 1976-80 & $224.000 / 44.800$ (ano) \\
\hline 1981-85 & 208.900/41.780 (ano) \\
\hline 1986-90 & $181.100 / 36.200$ (ano) \\
\hline Eurostat & N/ano \\
\hline 2008 & 8.800 \\
\hline 2009 & 14.217 \\
\hline 2010 & 16.079 \\
\hline 2011 & 11.860 \\
\hline 2012 & 9.326 \\
\hline 2013 & 9.744 \\
\hline 2014 & 7.865 \\
\hline 2015 & 12.712 \\
\hline 2016 & 11.790 \\
\hline 2017 & 13.830 \\
\hline 2018 & 14.570 \\
\hline
\end{tabular}

Fontes: Cónim (1984) para os valores até 1970; Amaro (1985: 606) para valores até 1980; Cónim (1984b) para as estimativas até 1985; Martins (2004) para o primeiro valor de 1986-1991 e o de 1996-2001; Rallu, Munoz-Perez \& Carrilho (2000) para o segundo valor de 1986-1991; Oliveira et al. (2016) para os valores de 2001-2011; Eurostat para os valores entre 2008 e 2018, atualizados em junho de 2020 (com base no que o INE disponibiliza, de acordo com o Inquérito à Mobilidade e o SEF, respeitam a números de entradas/ imigração de nascidos em Portugal, independentemente da nacionalidade). 
8. Poinard utiliza o termo de "melhor estar" para definir as a categoria de emigrantes que conseguiram, com a emigração, melhorar a sua situação de vida com a aquisição de uma casa, que também asseguraram a reforma, que tinham "vencido na vida" (Poinard, 1983b: 278).
Norte e Centro havia mais população a regressar, pois também foi aí que houve mais emigração para o Brasil. Entre 1960 e 1964 identifica-se o encerramento do ciclo migratório brasileiro. Entre 1965 e 1973 diminuíram os regressos e, entre 19701973, os quantitativos por distrito não atingiam sequer os 3.000 (Santos, 1991).

Neste período também se publicavam estimativas. Quer com base em cálculos do passado, quer pela perceção, através do comportamento dos emigrantes - pelas férias anuais, a ligação a Portugal, os interesses manifestados na economia local e algum investimento em habitações - acreditava-se, no início dos anos 1980, que o regresso da categoria de emigrantes considerados em "melhor estar"8 obtido com a emigração, continuaria durante muito tempo (Poinard, 1983b). Na década de 1980, previa-se que regressariam a Portugal, em especial vindos da Europa, cerca de metade do total de emigrados desde 1950 (Silva, 1984: 213). Os regressos continuaram durante os anos 1990, diminuindo de intensidade e contemplando, em número crescente, emigrantes em idade de pré-reforma (Roca, 2000: 45).

Num estudo quantitativo feito com base nos censos de 1991, são analisados os regressos da década anterior, com destaque para a proveniência de países europeus (Rallu, Munoz-Perez \& Carrilho, 2000). Foram contabilizados 102.825 regressados que viviam fora de Portugal em 1985 e 47.688 que viviam fora em 1989, o que indica a continuação da dinâmica de regressos. França é o país de proveniência com maior representação, com 40\% de regressados entre 1986 e 1991. São da Europa 55\% de regressados entre 1986-1991 e 60\% no período entre 1990-1991 (Rallu, Munoz-Perez \& Carrilho, 2000).

Isabel Oliveira e colegas indicam que, na primeira década de 2000, regressaram a Portugal 233 mil indivíduos, conforme aferição pelas respostas às perguntas retrospetivas dos censos (2011) aos residentes no país, nomeadamente sobre se teriam residido durante mais de um ano no estrangeiro (Oliveira et al., 2016). O foco da análise incidiu sobre 214 mil daqueles (nascidos em Portugal) que tinham pelo menos 20 anos à data do censo. Neste estudo evidencia-se um novo perfil de emigrantes, decorrente também de novos destinos e de um novo contexto mundial das migrações internacionais, por comparação com o perfil da emigração tradicional. Uma análise da última década demonstra que entre 2013 e 2014 os regressos descem para os valores mais baixos, que atingem os 7.865 regressos, em 2014. Ou seja, durante o período da crise financeira de 2008-2015, os portugueses emigraram mais do que regressaram. A partir de 2015 os valores voltam a subir, tendo sido 14.570 regressos em 2018. De acordo com os dados do Eurostat a tendência mais recente é, novamente, a de aumento dos contingentes de regresso. Reforça-se que o regresso de emigrantes continuou pelo século XXI, pois "mais do que um projeto 
imaginado, os fluxos são numerosos e consistentes ao longo da primeira década do século" (Oliveira et al., 2016).

\section{A diversificação da emigração e dos regressos}

A análise do perfil do emigrante regressado nas últimas décadas revela uma diferenciação ao longo do tempo que se fica a dever à história da emigração portuguesa e à diversificação dos destinos migratórios. Os regressos que resultam da emigração tradicional são oriundos dos principais países europeus de destino da emigração, como a França, a Alemanha ou a Suíça. Os regressos resultantes da emigração mais recente têm, subjacente, uma maior diversidade de destinos e de perfis de emigrantes (Marques et al., 2020), o que resulta numa maior diversidade de perfis.

As migrações de regresso a Portugal na década de 1980 - sobre as quais mais se sabe - começam por ser tendencialmente mais masculinizadas (Amaro, 1985b; Rallu, Munoz-Perez \& Carrilho, 2000) de forma consistente com a emigração laboral que the esteve na origem. À medida que as famílias se juntaram aos homens, a emigração foi-se tornando mais feminina e diversificada (assim como os regressos). Em termos etários, quase $60 \%$ da população regressada ao continente no período entre 1974 e 1980 tinha, em 1981, entre 30 e 59 anos e cerca de 20\% entre sete e 14 anos (Amaro 1985b). Os regressados tinham comparativamente menos pessoas com mais de 65 anos do que a população residente (7,1\% contra 18\%).

No caso do movimento oriundo das ex-colónias, também sublinhamos a forte presença de juventude na população, sobretudo porque no recenseamento de 1981 a maioria deste regresso tinha ocorrido alguns anos antes. A estrutura etária para o período 1974-1980 é mais jovem nesta população do que na residente no continente, em 1981, na maioria dos escalões até aos 49 anos: só $20 \%$ tinham 50 e mais anos em 1981 (31\% no total da população), e 43\% do total de "retornados" tinha entre os 9-19 anos e os 30-39 anos (Amaro, 1985b).

De uma forma geral, os emigrantes regressados possuíam uma escolaridade baixa e semelhante à que detinham quando saíram (já os "retornados" tendem a demonstrar um ganho de escolaridade no seu percurso migratório). Cerca de $92 \%$ dos regressados não tinham qualquer grau escolar ou possuíam apenas a escolaridade obrigatória (Pisco \& Seruya, 1984).

Na comparação por países de emigração sobressai uma taxa muito mais elevada de conclusão da escola primária nos ex-emigrantes na Alemanha, do nos ex-emigrantes 
9. A exceção ao perfil pouco escolarizado entre emigrantes que voltaram a Portugal encontra-se, como já foi afirmado, entre os "retornados" de África. De facto, "com escolaridade, por vezes superior a básica, e com diversos cursos de formação, estes emigrantes enquadram-se rapidamente em atividades diversas, determinando o seu entusiasmo profissional, situações de liderança e investimento a que a população residente se mostra mais indiferente" (Santos, 1991: 362). Estes "retornados" detinham ainda um capital empreendedor que constitui um fator de integração importante, tendo mesmo criado postos de trabalho que não se destinaram apenas a outros "retornados", mas, igualmente, à população residente nas localidades para onde voltaram. de França (76\% contra 46\%). Estudos realizados ao nível local revelam a tendência de baixa escolaridade dos regressados, sendo a quarta classe o grau mais elevado obtido pela maioria dos inquiridos no Nordeste Interior (Cepeda, 1991), assim como numa pesquisa posterior realizada no concelho de Ponte de Lima (Roca, 2000).

Em consonância com a afirmação de que a escolaridade não aumentou com a emigração, é residual a proporção dos que obtiveram formação profissional no estrangeiro (85\% dos regressados não o fizeram) (Pisco \& Seruya, 1984; Silva, 1984). Esta evidência é corroborada por resultados ao nível local: cerca de $25 \%$ dos regressados ao Nordeste Interior frequentaram cursos de formação profissional nos domínios da reparação de máquinas agrícolas e automóveis e eletromecânica, o que, segundo Cepeda (1991), não terá tido qualquer impacto na utilização de novas tecnologias com vista ao desenvolvimento ${ }^{9}$. À partida, os emigrantes também não eram muito qualificados profissionalmente, já que nos censos de 1975, pelo menos em França, o contingente de portugueses contramestres e operários profissionais não atingia os $40 \%$ e, destes, mais de metade residia em França há mais de 15 anos (Poinard 1983a).

Profissionalmente, os emigrantes estiveram inseridos sobretudo na construção civil, indústria e agricultura nos países de acolhimento. No recenseamento de 1975, 47\% dos emigrados portugueses em França exerciam atividade na construção civil (Poinard, 1983a: 49). Em comparação com a profissão à saída de Portugal, assinala-se a perda de importância do setor primário e a deslocação para o setor do comércio, restaurantes e hotéis (Amaro, 1985b; Silva, 1984), em particular no caso das muIheres, pois cerca de $33 \%$ das portuguesas emigradas trabalham neste setor, contra 14\% dos homens (Amaro, 1985b: 653). Nos dados trabalhados por Poinard, 70\% das mulheres regressadas encontravam-se a trabalhar em Portugal, um "número superior ao do conjunto das suas companheiras instaladas em França e até mesmo ao do conjunto das francesas" (Poinard, 1983a: 275). Segundo o estudo do IED, 6\% dos inquiridos declararam-se desempregados, o que equivale a uma taxa de desemprego de $11 \%$ para o total, $15 \%$ no caso das mulheres (Amaro 1985b). Este valor é mais elevado do que a taxa de desemprego da população do continente em 1981 (7\%) e dos residentes no estrangeiro em 31 de dezembro de 1979 (Amaro 1985b).

A taxa de inserção económica em Portugal foi mais elevada entre os regressados que trabalhavam na construção civil ou na indústria no estrangeiro, mesmo que a sua inserção após o regresso tenha tido lugar no sector da agricultura - 71\% dos ativos na agricultura tinham estado empregados naqueles setores aquando emigrados (Silva 1984). Na maioria dos que se inseriram numa profissão agrícola após o regresso, houve um regresso às suas profissões de origem, pois tinham desempenhado uma atividade nesse setor em Portugal (Amaro, 1985b; Martins, 2003). 
No censo de 1991 assinala-se uma tendência semelhante ao já verificado sobre os movimentos de regresso europeu: a média de idades no caso dos regressados de França e Alemanha, no período 1990-1991, é de 43 anos. Estes são mais velhos do que os regressados da Suíça no mesmo período (média de idades de 31 anos). A proporção de idosos também é menor (Rallu, Munoz-Perez \& Carrilho, 2000).

Deve ser reforçado o que se mantém nos resultados dos censos de 1991 e vinha de antes: a ideia de que ao regresso se associava a reforma continua a não se verificar de forma predominante, pois os regressados são maioritariamente jovens e vêm com descendentes. Como refere Amaro,

\begin{abstract}
ao contrário do que muitas vezes se pensa, o regresso não traz para o país uma população envelhecida e completamente gasta/usada pelo capitalismo europeu [...] mas sim uma população predominantemente em idade ativa, trazendo consigo uma segunda geração à procura de enraizamento e de futuro (Amaro, 1985b: 632).
\end{abstract}

Cepeda (1991) também refere a idade ativa no regresso ao Nordeste português e salienta que

\begin{abstract}
ao contrário do que muitas pessoas julgavam, [o regresso] não traz para esta Região uma população envelhecida e saturada, mas sim um capital humano em idade predominante ativa, capaz de contribuir com a sua quota-parte para o progresso do Nordeste Interior. De igual modo o regresso dos emigrantes faz-se acompanhar, em número significativo, de uma segunda geração ávida de enraizamento e de futuro, potencial embrião de agentes inovadores (Cepeda 1991: 29).
\end{abstract}

Na análise dos regressos com base nos censos de 1991, Rallu e colaboradores relacionaram as taxas de regresso de França e da Suíça para Portugal com variáveis sociodemográficas, como sexo, idade, período de emigração e nível de escolaridade. Nas taxas de regresso por sexo, os autores mostram que os retornos de França e da Suíça são masculinizados: 23 mulheres contra 19 por mulheres (por 1.000) regressadas de França entre 1990 e 1991, e 40 homens (por 1.000) para 37 mulheres (por 1.000), no caso da Suíça (Rallu, Munoz-Perez \& Castilho, 2000).

As taxas de regresso de França, por idade, estão acima de $10 \%$ no jovem adulto e aumentam para $20 \%$ nos homens entre os 40 e 49 anos. São mais de $60 \%$ entre os 60 e os 64 anos. A taxa de regresso é de 60\%o para homens entre os 20 e os 49 anos no caso da Suíça, o que, em comparação com a França, resulta da natureza diferencial dos fluxos migratórios para um e outro país, pois no primeiro caso en- 
volvia mais trabalhadores contratados que regressaram após o fim do contrato, enquanto a emigração França se caracterizava- por uma maior migração de fixação (Rallu, Munoz-Perez \& Carrilho, 2000).

Na escolaridade confirmam-se os níveis baixos que haviam sido já apontados previamente, quer de França, como da Suíça. Os regressados em 1986 apresentam com maior frequência qualificações ao nível do ensino básico e em menor proporção de qualificações de nível secundário, em comparação com a população total, isto no grupo entre os 20 e os 39 anos. No caso dos regressados da Alemanha assinala-se o contrário, pois os regressados são mais qualificados do que a população residente. Entre os mais velhos, os níveis de escolaridade são mais baixos do que na população total, o que não surpreende dado o padrão migratório dominante na emigração intraeuropeia dos anos 1960 e 1970, marcado pelo recrutamento de forças de trabalho manual para suprir necessidades do mercado de trabalho local nos países do norte da Europa (Rallu, Munoz-Perez \& Carrilho, 2000).

Havia menos migrantes regressados empregados do que no total da população (como já tinha sido verificado no censo anterior), principalmente nos regressados depois de 1989. As taxas de desemprego dos homens são mais elevadas do que na população total, mais para os que regressaram entre 1990 e 1991, do que nos regressados entre 1986 e 1991 (taxa três ou quatro pontos superior), em idades adultas. Trata-se de um indicador que indicia que os regressados tiveram dificuldade em se reinserir no mercado de trabalho português. A situação para as mulheres é similar (Rallu, Munoz-Perez \& Carrilho, 2000).

Relativamente aos setores de atividade, e em consistência com os dados dos estudos anteriores, os regressados trabalhavam em maior proporção que a população total na agricultura, excetuando mulheres regressadas da Alemanha e da Suíça. Também estavam menos frequentemente na indústria, exceto os homens que regressavam da Alemanha. A construção empregava uma proporção semelhante de homens regressados de França e da Suíça (em redor de 25\%). No ramo de atividade dos serviços, os regressados encontravam-se ativos mais no comércio e restauração e menos na banca e seguros. As mulheres regressadas estavam mais no setor terciário do que a população total, e os homens, principalmente de França, inseriam-se menos nos serviços (Rallu, Munoz-Perez \& Carrilho, 2000).

Estudos locais publicados a partir do ano 2000 repetem o que se havia verificado no âmbito nacional: os portugueses emigrados passaram de assalariados agrícolas a trabalhadores da construção civil e a operários durante a emigração, acumulando, não raramente, as duas atividades. As mulheres são domésticas ou assalariadas 
(Roca, 2000; Portela \& Nobre, 2001). Quando regressam, os ex-emigrantes retomam a atividade agrícola, embora tendo progredido profissional e socialmente, passando de assalariados a proprietários (de terras, plantações ou gado) (Portela \& Nobre, 2001). Noutros casos, o regresso faz-se para os sectores da construção civil, comércio e serviços, ou para a inatividade, sobretudo por reforma (Roca, 2000).

A maior diferença entre os regressos do século XX e os do século XXI consiste na diversificação dos países de partida desses regressos, o que tem subjacente uma lista maior de destinos de emigração e um perfil de emigrantes e regressados também mais heterogéneo (Peixoto et al., 2019; Góis \& Marques 2020). De 18 países regressaram mais de mil emigrantes, e França é o país de onde mais se regressou, com $27 \%$ do total (Oliveira et al., 2016). A Suíça e a Alemanha (destinos tradicionais) têm proporções mais baixas, mas também a Espanha e o Reino Unido, destinos da nova emigração. Estes cinco países contabilizam $70 \%$ dos regressos constituídos por uma população heterogénea e polarizada em termos de emigração recente e tradicional (Oliveira et al., 2016).

Ao considerar o conjunto dos regressados, o seu perfil revela algumas distinções relativamente à população residente no país:

i. maior percentagem de homens do que a média da população, pois a emigração também foi mais masculina;

ii. mais juventude do que na população residente, traduzida pelos regressos na idade ativa e não apenas na reforma, como também já acontecia com os regressos tradicionais; e

iii. mais desemprego no grupo de regressados do que no conjunto da população residente.

Também são evidentes algumas semelhanças entre a população regressada e a população residente:

i. o nível de escolaridade média entre 7,3 e 7,8 anos de escolaridade em ambos os grupos; e

ii. os reformados têm proporções idênticas nos dois grupos (Oliveira et al., 2016).

Ao analisar o regresso por país de emigração, os autores tipificam três perfis. 
i. Migrações de regresso tradicionais provenientes de França e de outros países de emigração mais antiga, com migrantes em idades próximas de 60 anos, com baixa escolaridade e cerca de metade de reformados constituem o primeiro tipo.

ii. Um segundo tipo de regressos parte de países de emigração mais recente, como Suíça, Espanha e Reino Unido, constitui-se de indivíduos com idade média de 40 anos, escolaridade mais elevada, elevada taxa de desemprego e com poucas situações de reforma.

iii. Os regressados de países lusófonos como o Brasil, Angola e Moçambique têm em média 44 anos, profissões qualificadas antes e após o movimento, e são poucas as situações de reforma ou desemprego. Este último tipo de regressados caracteriza-se, ainda, por permanências temporárias nos postos de trabalho naqueles destinos (Oliveira et al., 2016).

\section{O apelo afetivo como justificação para o regresso}

As razões para regressar são um dos temas recorrentes nos estudos sobre o regresso a Portugal. Embora exista uma evidência de, no passado, ter havido um acúmulo de regressos devido às crises petrolíferas de 1973 e de 1979, também é verdade que houve emigrantes a permanecer, assim como outros fatores produzem regressos ao longo do tempo e que poderão não ser imputáveis a fatores estruturais e/ou exclusivamente económicos. Encontram-se na literatura científica elementos que problematizam esta linearidade na análise, mesmo no período das crises enunciadas, nomeadamente no inquérito a regressados realizado por Poinard, onde se confirma a reduzida importância da crise económica ou do desemprego nos regressos dos trabalhadores migrantes portugueses, referindo que mais de $80 \%$ tinham um emprego quando tomaram a decisão de voltar a Portugal (Poinard 1983b: 294).

O inquérito supracitado do IED vai no mesmo sentido, pois as razões elencadas são maioritariamente de ordem afetiva (saudades da família e da terra), familiar (educação dos filhos em Portugal), ou outras, aqui designadas como "esbatimento da relação repulsão-atração por razões extraeconómicas", referidas por 35\% dos entrevistados. A "anulação ou enfraquecimento do vetor atração" - como a falta de trabalho -, o regresso imposto pelo país de imigração ou a opção pelo subsídio de regresso dado pelo país de imigração teve apenas $6 \%$ de referências. Devemos ainda frisar que $17 \%$ dos entrevistados referiram ter regressado por razões de saúde (Amaro, 1984: 184). 
Da análise dos processos de regressados com ajudas de apoio ao regresso do Estado francês, feita por Poinard, ressalta uma conclusão que corrobora a reduzida relevância da falta de trabalho nos projetos de regresso, pois havia apenas $17 \%$ de desempregados portugueses entre o conjunto dos requerimentos, contra $33 \%$ no total dos estrangeiros, o que sustenta a afirmação de que "seriam muitos os que receberam a subvenção por ocasião de um regresso já projetado" (Poinard, 1983a: 33). No inquérito a regressados, é reforçada esta conclusão, referindo que a medida de apoio ao regresso

\begin{abstract}
facilitou sem dúvida o regresso de um certo número de trabalhadores idosos desempregados há muito tempo, mas, seguidamente, encorajou mais notoriamente certos imigrantes no seu projeto de regresso, projeto para o qual ela [a medida] não os tinha incitado. [...], ela reforçou e precipitou uma decisão que muitos emigrantes, divididos entre os laços da nova vida no estrangeiro e a nostalgia do país, adiavam de boa vontade para mais tarde (Poinard 1983a: 56).
\end{abstract}

Estudos de âmbito regional também reforçam esta informação. Aproximadamente $35 \%$ dos inquiridos em estudo sobre o Nordeste Interior invocaram razões não económicas, como saudades da família e da terra e a necessidade de educar os filhos em Portugal (tentando evitar que estes quisessem fixar-se no país de destino). Por motivos de saúde, reforma e acidentes de trabalho regressaram $24 \%$ dos inquiridos. São igualmente diminutas as justificações relativas ao fim do trabalho, a opção pelo subsídio de regresso e a imposição do país de acolhimento, com 13,6\% de referências (Cepeda, 1991: 25-26).

No outro estudo de âmbito local referenciado, a perda de emprego nunca surge como impulsionadora do regresso. A pretensão de educar os filhos em Portugal, problemas de saúde de um membro da família, ou ter satisfeito aspirações económicas e de condições de trabalho, além de causas imprevistas, são as razões apresentadas com maior frequência pelos inquiridos (Portela \& Nobre, 2001: 1133). Acrescenta-se que a obtenção de autonomia com o regresso, designadamente trabalhar por conta própria, pode ter sido uma forte motivação (Portela \& Nobre, 2001).

Estes estudos poderão ter incluído regressados já após a entrada de Portugal na então - Comunidade Económica Europeia e nos bons auspícios que se desejavam para o país, mas tal não é referido como sendo uma das motivações, crê-se que porque a maioria dos regressos centra-se em período anterior. 


\section{Notas finais}

O regresso constitui um objeto de estudo, de estudo complexo, em que, além da trajetória do migrante, da família, e de seus recursos demográficos e sociais, é necessário considerar os fatores estruturais do país de origem e dos países de destino. De alguma forma, não difere muito do que é feito quando se estuda a emigração mas, enquanto nesta a experiência de vida fora ainda é desconhecida, no caso do regresso há um conhecimento prévio, mais ou menos desatualizado consoante o tempo de permanência no país de acolhimento, de para onde se muda, e com uma perceção intercetada pela experiência migratória. O retorno físico não é, como no imaginário do imigrante, "um retorno a si, um retorno ao tempo anterior à emigração, uma retrospectiva" (Sayad, 2000: 12).

Nos diversos estudos analisados nas páginas precedentes, um conjunto vasto de variáveis com influência nas intenções de regresso e no regresso concretizado, bem como na reinserção no país de origem, são tomadas em consideração. A representação do regresso, ou sua concretização, derivam, assim, de contingências históricas e sociais que condicionam opções migratórias, e não de "uma predisposição imutável de um grupo ou de uma comunidade para o enraizamento no país natal" (Costa 2001:80).

O regresso, tal como a emigração inicial, faz parte integrante da história das migrações em que Portugal é origem e destino. As caraterísticas dos regressados aproximam-se daquelas que é possível observar nos emigrantes no fluxo de saída. De uma maneira geral, os regressados foram capazes de acumular algum capital e usaram-no para um movimento de ascensão social, por vezes para saírem da pobreza, ou para adquirirem níveis de conforto doméstico e social que anteriormente não detinham e que a permanência em Portugal poderia ter comprometido. Em períodos distintos da emigração portuguesa, ao longo dos últimos 60 anos, adquirir ou construir uma casa, investir do capital acumulado, ajudar familiares, pagar a educação dos filhos são alguns dos destinos da poupança, das pensões de reforma ou das indemnizações laborais adquiridas no estrangeiro.

As motivações para o regresso captadas pelos estudos empíricos analisados dão conta da diversidade de fatores que poderão intervir na decisão de regressar ao país de origem. Apesar de surgirem muitas vezes de forma objetivada, elas resultam de um processo de racionalização da decisão tomada. Contudo, a resolução de regressar nem sempre tem razões facilmente identificáveis, como nota Poinard quando afirma que 
a impressão que prevalece, de tal modo o regresso parece por vezes súbito, inopinado, é que, passado o nível de economia considerado suficiente, um certo número de dificuldades, de privações, de separações até aí suportadas se tornam intoleráveis (Poinard 1983b: 279).

De facto, de acordo com um inquérito às perceções dos regressados sobre o projeto migratório, $25 \%$ consideram que tiveram sucesso, $50 \%$ consideram que vivem melhor do que antes da partida, mesmo sem terem alterado a sua posição social, e apenas $25 \%$ consideram que falharam (Poinard 1983b). Também em estudos locais há uma tendência para os ex-migrantes considerarem a emigração um projeto bem-sucedido, pois a maioria dos inquiridos encontra-se "entre o desapontamento parcial com a migração e o êxito retumbante" (Portela \& Nobre, 2001: 1137).

Assim, as razões do regresso serão, frequentemente, uma combinação de fatores estruturais inerentes às sociedades de origem e/ou de acolhimento (como também na migração original) e de condições de agência do próprio emigrante. Isso mesmo notam Portela e Nobre, quando frisam que o regresso

parece ser decidido tendo em conta o peso da combinação dos fatores positivos e negativos nos dois espaços em causa. Tanto a acumulação das poupanças antevistas e/ou recebimento de indemnização e/ou pré-reforma como os salários reduzidos, o cansaço da falta de autonomia no trabalho e/ou os impostos elevados, tudo isto em França, concorrem para o regresso. Em Portugal, acham-se estímulos complementares: a construção da casa, a aquisição de terras, a receção de bens de herança e a possibilidade de trabalho por conta própria (Portela \& Nobre, 2001: 1130).

Permanece atual a afirmação de que

o alcance e, sobretudo, a permanência deste fenómeno dependem da criação de condições favoráveis à fixação das populações (condições de vida e de emprego) e à atenuação das desigualdades de oportunidades, tanto a nível nacional como no confronto com os demais países europeus (relação de forças de atração e repulsão)? (Silva, 1984: 215).

A relevância da emigração e do regresso na sociedade portuguesa exigem que os estudos analisados neste artigo possam ser complementados com análises aprofundadas e atualizadas sobre os motivos que explicam estes movimentos, as condições estruturais e conjunturais que os enquadram e os seus efeitos nos diferentes sistemas sociais da sociedade portuguesa e nas biografias dos migrantes. Questões 
geracionais e os tempos de permanência fora de Portugal também devem ser fatores a tomar em consideração em estudos futuros.

Novos estudos contribuirão também para alimentar discussões sobre a polissemia do conceito de regresso, que pode ser também verificada nos novos perfis da emigração portuguesa e nas novas dinâmicas que lhe são inerentes e que o desafiam com mais premência como fim do ciclo migratório, esbatendo as suas fronteiras, acompanhando a tendência internacional para considerar que a circularidade migratória, o espaço transnacional e as atividades transnacionais ganham importância e uma dimensão cada vez maior na reflexão sobre o que significa isto de "regressar" ao país de onde se emigrou, em particular quando a emigração portuguesa acontece maioritariamente na geografia de livre circulação da União Europeia. O regresso como fecho de um ciclo de emigração é uma das definições possíveis de regresso, mas há muito que não é a única.

\section{Referências}

ALVES, Jorge Fernando. Os brasileiros. Emigração e retorno no Porto Oitocentista. Tese (Doutoramento), Faculdade de Letras da Universidade do Porto, 1994.

AMARO, Rogério Roque. Ei-los que voltam: problemas e desafios do regresso dos emigrantes. Revista Crítica de Ciências Sociais, n. 15, 16 e 17, p. 351-373, 1985a.

Reestruturações demográficas, económicas e socioculturais em curso na sociedade portuguesa: o caso dos emigrantes regressados. Análise Social, n. 87, 88 e 89, p. 605-677, 1985b.

Retorno, emigração e desenvolvimento regional. In: SILVA, M. (Org.). Retorno, emigração e desenvolvimento regional em Portugal, p. 165-234. Lisboa: Instituto de Estudos para o Desenvolvimento, 1984.

BRETTELL, Caroline. We have already cried many tears:Portuguese women and migration. Cambridge, MA: Schenkman Pub. Co., 1983.

Emigrar para voltar: a portuguese ideology of return migration. Papers in Anthropology, n. 20, p. 1-20, 1979.

CANDEIAS, Pedro; MARQUES, José Carlos; PEIXOTO, João. Emigração portuguesa: bibliografia comentada (1980-2013). Socius Working Papers, n. 1, 2014. Disponível em: <http://hdl.handle.net/10400.5/8338>. 
CEPEDA, Francisco . Emigrantes regressados e desenvolvimento no Nordeste Interior português. Bragança, PT: Instituto Politécnico de Bragança, 1991.

CÓNIM, Custódio. Caracterização do fluxo de retornos 1960-70. In: Silva, M. (Org.). Retorno, emigração e desenvolvimento regional em Portugal, p. 27-47. Lisboa: Instituto de Estudos para o Desenvolvimento, 1984a.

CÓNIM, Custódio. Previsão do retorno na década de 80. In: Silva, M. (Org.). Retorno, emigração e desenvolvimento regional em Portugal, p. 49-61. Lisboa: Instituto de Estudos para o Desenvolvimento, 1984b.

CORREIA, Gabriela. Motivações para um eventual regresso de emigrantes a Portugal. Revista Migrações, n. 12, p. 39-67, 2015.

COSTA, Joaquim. Lugares de partir, lugares de voltar: espaços de regresso na emigração portuguesa. Discursos [em linha]: Língua, Cultura e Sociedade, número especial, p. 79-87, Fev. 2001.

DELICADO, Ana. O retorno dos "cérebros": regresso e reintegração dos investigadores portugueses em mobilidade. Revista Iberoamericana de Ciencia, Tecnología y Sociedad, v. 5, n. 15, p. 185-218, 2010.

FONTES, Margarida. Scientific mobility policies: how Portuguese scientists envisage the return home. Science and Public Policy, v. 34, n. 4, p. 284-298, 2007.

GÓIS, Pedro; MARQUES, José Carlos. Portuguese intra-EU migration. The dynamics of an ongoing migration process. Racial and Ethnic Studies, 2000 (forthcoming).

GÓIS, Pedro, MARQUES, José Carlos; PINHO, Filipa. Regresso de uma geração preparada. Diagnóstico de situação atual e Modelo Prospetivo de Desenvolvimento. Porto, PT: Fundação AEP, 2017.

KING, Russell; CHRISTOU, Anastasia. Of counter-diaspora and reverse trasnationalism: return mobilities to and from the Ancestral homeland. Mobilities v. 6, n. 4, p. 451-466, 2011.

Cultural geographies of counter-diasporic migration: perspectives from the study of second-generation "returnees" to Greece. Population, Space and Place, v. 16, n. 2, p. 103-119, 2010.

LEANDRO, Maria Engrácia. Reinserção familiar no centro das antinomias dos processos migratórios internacionais. Um estudo de caso em situação de regresso. Sociedade e Cultura, n. 4, Cadernos do Noroeste, "Série Sociologia", v. 18, n. 1-2, p. 25-73, 2002. 
MAIA, Fernanda. Os "brasileiros" de torna-viagem e as relações Portugal-Brasil na década de 1930 - estudo de caso. In: SOUSA, F. (Org.). Nas duas margens. Os portugueses no Brasil, p. 163-175. Porto, PT: Cepese; Edições Afrontamento, 2009.

MARQUES, José Carlos; CANDEIAS, Pedro; GÓIS, Pedro; PEIXOTO, João. Is the segmented skill divide perspective useful in migration studies? Evidence from the Portuguese case. Journal of International Migration \& Integration, 2020.

MARTINS, Fernando. O regresso de emigrantes portugueses, entre 1975-2001. V Congresso da Geografia Portuguesa. "Portugal: territórios e protagonistas". Guimarães, PT: Universidade do Minho; Associação Portuguesa de Geógrafos, 2004.

O regresso de emigrantes portugueses ao Pinhal Interior Sul,entre 1974 e 2001. GeolNova, n. 8, p. 147-180, 2003.

MARTINS, José. Emigrantes, retornados, regressados e mudança numa comunidade da Beira-Interior. Povos e Culturas, n. 1, p. 149-166, 1986.

MONTEIRO, Miguel. Migrantes, emigrantes e "brasileiros" de Fafe (1834-1926): territórios, itinerários e trajectórias. Dissertação (Mestrado em História das Populações) - Instituto de Ciências Sociais, Universidade do Minho, Fafe, 2000.

NETO, Félix. Re-acculturation attitudes among adolescents from returned Portuguese immigrant families. International Journal of Intercultural Relations, v. 34, n. 3, p. 221-232, 2010.

NETO, Félix. Predictos of loneliness among Portuguese youths from returned migrant families. Social Indicators Research, v. 126, n. 1, p. 425-441, 2016.

NETO, Félix: NETO, Joana. Satisfaction with life among adolescents from returned Portuguese immigrant families. Journal of Social Research \& Policy, v. 2, n. 2, p. 2746, 2011.

OLIVEIRA, Isabel. Emigração, retorno e reemigração na primeira metade do século XX. Análise Social, n. 184, p. 837-852, 2007.

OLIVEIRA, Isabel; CANDEIAS; Pedro; PEIXOTO, João; AZEVEDO, Joana; MALHEIROS, Jorge. Regresso e circulação de emigrantes portugueses no início do século XXI. Sociologia, Problemas e Práticas, n. 81, p. 11-35, 2016.

OLIVEIRA, Isabel; CANDEIAS, Pedro; PEIXOTO, João; MALHEIROS, Jorge; AZEVEDO, Joana. Regressos de emigrantes portugueses, 2001-2011. OEm Fact Sheets, 2017. 
PEIXOTO, João; CANDEIAS, Pedro; FERREIRA, Bárbara; OLIVEIRA, Isabel; FERREIRA; Bárbara; OLIVEIRA, Isabel; MARQUES, José Carlos; GÓIS; Pedro; MALHEIROS, Jorge; MADEIRA, Paulo; SCHILTZ, Aline; FERRO, Alexandra; SANTANA, Eugénio. New emigration and Portuguese society: transnationalism and return. In: PEREIRA, C.; AZEVEDO, J. (Orgs.). New and old routes of Portuguese emigration. Berlin: Springer, 2019. Disponível em: <http://hdl.handle.net/10400.8/4005>.

PEIXOTO, João; OLIVEIRA; Isabel; AZEVEDO, Joana; MARQUES, José Carlos; GÓIS, Pedro; MALHEIROS, Jorge; MADEIRA, Paulo. Regresso ao futuro: a nova emigração e a sociedade portuguesa. Lisboa: Gradiva, 2016.

PEREIRA, Cláudia ; PINTO, Nuno; PIRES, Rui. Portuguese nurses in the UK 2014 / Enfermeiros portugueses no Reino Unido 2014. OEm Fact Sheets, n. 3, 2015.

PEREIRA, Sónia; SIQUEIRA, Sueli. Migração, retorno e circularidade: evidência da Europa e Estados Unidos. Rev. Interdiscipl. Mobil. Hum, n. 41, p. 117-138, 2013.

PILOTO, Adelina. O Concelho de Vila do Conde e o Brasil: emigração e retorno (18651913). Tese (Doutoramento em História) - Universidade do Porto, Porto, 2010.

PIRES, Rui. Migrações e Integração. Teoria e aplicações à sociedade portuguesa. Oeiras, PT: Celta, 2003.

PIRES, Rui; MACHADO, Fernando; PEIXOTO, João; VAZ, Maria João. Portugal. Atlas das migrações internacionais, Lisboa: Tinta-da-China; Fundação Calouste Gulbenkian, 2010.

PIRES, Rui; SILVA, Manuela. Os retornados: um estudo sociográfico. Lisboa: Instituto de Estudos para o Desenvolvimento, 1987.

PISCO, Manuel; SERUYA, Luís. O perfil socioeconómico do emigrante retornado. In: SILVA, M. Retorno, emigração e desenvolvimento regional em Portugal, p. 65-109. Lisboa: Instituto de Estudos para o Desenvolvimento, 1984.

POINARD, Michel. Emigrantes portugueses: o regresso. Análise Social, v. 19, n. 75, p. 29-56, 1983a.

. Emigrantes retornados de França: a reinserção na sociedade portuguesa.

Análise Social, v. 19, n. 76, p. 261-296, 1983b.

PORTELA, José; NOBRE, Sílvia. Entre Pinela e Paris: emigração e regressos. Análise Social, v. 36, n. 161, p. 1105-1146, 2001. 
RALLU, Jean; MUNOZ-PEREZ, Francisco; CARRILHO, Maria José. Return migration from Europe to Spain and Portugal. Studi Emigrazione, v. 37, n. 139, p. 625-650, 2000.

ROCA, Maria da Nazaré. Migração de regresso e desenvolvimento rural sustentável: um novo paradigma para as áreas rurais. Geolnova, n. 1, p. 34-50, 2000.

ROCHA-TRINDADE, Maria Beatriz. O regresso imaginado. Nação e Defesa, n. 28, p. 87-97, 1984.

ROCHA-TRINDADE, Maria Beatriz; ARROTEIA, Jorge. Bibliografia da emigração portuguesa. Lisboa: Centro de Estudos de História e Cultura Portuguesa; Instituto Português de Ensino a Distância, 1984.

RODRIGUES, Mélanie. A emigração feminina no concelho da Figueira da Foz com destino a França : (1960-1975). Dissertação (Mestrado em História, especialidade História Contemporânea: Economia, Sociedade e Relações Internacionais) - Faculdade de Letras da Universidade de Coimbra, Coimbra, 2011.

ROWLAND, Robert. Brasileiros do Minho: emigração, propriedade e família. In: BETHENCOURT, F.; CHAUDHURI, K. (Orgs.). História da expansão portuguesa, p. 324347. Lisboa: Círculo de Leitores, 1999a.

Portugueses no Brasil: projectos e contextos. In: BETHENCOURT, F.; CHAUDHURI, K. (Orgs.). História da expansão portuguesa, p. 348-373. Lisboa: Círculo de Leitores, 1999b.

SANTOS, Maria Gloria dos Santos; BRETTELL, Caroline. Já chorei muitas lágrimas: crónica de uma mulher portuguesa imigrada em França - história de vida de Maria Glória dos Santos. Lisboa: Universidade Nova de Lisboa, 1978.

SANTOS, Norberto. Emigração e retorno: dinamismos locais da integração - Consequências do regresso de emigrantes nos concelhos de Sátão, Tondela e Viseu. Cadernos de Geografia, n. 10, p. 307-429, 1991.

SARDINHA, João . "Returning" second generation Portuguese-Canadians and Portuguese-French return motivations and sense of belonging. Journal of Mediterranean Studies, v. 20, n. 2, p. 231-254, 2011.

Even If the only thing for me to do Here" was to milk cows": Portuguese emigrant descendant returnees from Canada narrate pre-return desires and motivations. Diaspora: A Journal of Transnational Studies, v. 17, n. 3, p. 316-339, 2008. 
SAYAD, Abdelmalek. O retorno, elemento constitutivo da condição do imigrante. Travessia - Revista do Migrante, número especial: "Abdelmalek Sayad", p. 7-32, 2000.

SILVA, Manuela. O impacto regional do retorno de emigrantes. Estudos de Economia, v. 4, n. 2, p. 213-224, 1984a.

SILVA, Manuela (Org.). Retorno, emigração e desenvolvimento regional em Portugal. Lisboa: Instituto de Estudos para o Desenvolvimento, 1984b.

(c) $($ ) 8 (3) 
